\title{
Heat-Resisting Aluminized Coatings Modified by Chromium Addition Produced on Nickel-Based Alloys
}

\author{
Mateusz Kotkowiak $^{1} \cdot$ Adam Piasecki $^{1} \cdot$ Michał Kotkowiak $^{2} \cdot$ Michał Kulka $^{1}$
}

Received: 20 April 2018/Accepted: 16 August 2018/Published online: 31 August 2018

(C) The Author(s) 2018

\begin{abstract}
Aluminizing process is an important technology in which aluminum is introduced into the surface of base material. In this work, aluminized layers were produced by the pack cementation process on Inconel 600, Inconel 625 and Nimonic 90 nickel-based alloys. Powder mixture contained $80 \%$ of $\mathrm{Al}$ and $20 \%$ of $\mathrm{Fe}-\mathrm{Cr}$. Microstructure, hardness, chemical composition and heat resistance were investigated. The microstructure consisted of intermetallic phases near the surface, and below them, the solid solution was observed. The oxidation resistance at elevated temperature of alloys with the layer was compared with pure alloys. After 20 -h annealing at $1000{ }^{\circ} \mathrm{C}$, the phase analysis was carried out. On the Nimonic 90 with aluminized coatings, a lot of $\mathrm{Cr}_{2} \mathrm{O}_{3}$ and $\mathrm{Al}_{2} \mathrm{O}_{3}$ oxides were produced, whereas on the pure Nimonic 90 , a lot of $\mathrm{NiO}$ oxides were observed. It was found that the best heat resistance was obtained for the layer produced on the Nimonic 90.
\end{abstract}

Keywords Aluminum · Chromium · Pack cementation · Oxidation

Mateusz Kotkowiak

mateusz.kotkowiak@put.poznan.pl

1 Institute of Materials Science and Engineering, Poznan University of Technology, pl. M. Sklodowskiej-Curie 5, 60-965 Poznan, Poland

2 Institute of Physics, Poznan University of Technology, Piotrowo 3, 60-965 Poznan, Poland

\section{Introduction}

Ni-based alloys are modern materials which have a lot of important applications, for example, turbine blades in jet engines or some stuff for the heat treatment furnaces [1]. During the operation, turbine blades are exposed to inclement factors: high rotational speed at elevated temperatures, bending and torsional stress, which can cause blade failures. These failures can be grouped into two categories: high-cycle fatigue, low-cycle fatigue and creep rupture. $\mathrm{Ni}$ based alloys have to be characterized by good properties at high temperatures, such as excellent mechanical strength and creep resistance. The Ni alloys which are used in heat treatment furnaces have to be characterized by high oxidation resistance. The most effective alloying element for improving the heat resistance of superalloys, such as $\mathrm{Ni}$ based alloys, is chromium and aluminum [2-5]. To improve properties of Ni superalloys, surface technology is often applied, e.g., diffusion aluminizing is very popular. This process, producing nickel aluminides $+\mathrm{Al}_{2} \mathrm{O}_{3}$ coating on the surface, provides the appropriate heat resistance $[6,7]$ and can be used for various materials. Such coatings are formed on TiAl alloys [8], austenitic steel [9], Co-based superalloy $[10,11]$ or aforementioned Ni-based alloys [7]. It is also possible to produce these coatings on alloys such as $\mathrm{Fe}-30 \mathrm{Cr}$ and impure metals such as $\mathrm{Fe}, \mathrm{Ni}$ or Mo [12]. $\mathrm{Al}-\mathrm{Si}$ powder is often used in order to produce the aluminide coatings on Ni-based alloys [13]. Chromoaluminizing process is a technology in which chromium and aluminum are introduced in various proportions onto the surface of base material. After oxidation, the chromoaluminized coating consists of $\mathrm{Al}_{2} \mathrm{O}_{3}$ and $\mathrm{Cr}_{2} \mathrm{O}_{3}$ phases on the surface. This process can be used to modify the materials as follows: steel [1, 14], austenitic steel [15] or Ni-based alloys [16, 17]. 
In recent years, aluminizing and chromoaluminizing processes have intensively developed. One of them is the circulation method. It is a one-stage method in case of the aluminizing process. Chromoaluminizing is a two-stage process consisting of two stages: chromizing as the first treatment and aluminizing carried out after that. Microstructure of various coatings differ strongly and depend on the base material. The coatings produced on nickel alloys during chromoaluminizing process consist of intermetallic phases: $\mathrm{Ni}(\mathrm{Cr})-\Upsilon$ and $\mathrm{Ni}_{3} \mathrm{Al}-\Upsilon$ ' [17].

Pack cementation method is also often applied. Onestage process can also be used in case of aluminizing. The microstructure of aluminized materials consists of intermetallic phases $\mathrm{FeAl}$ and $\mathrm{Fe}_{3} \mathrm{Al}$ for $\mathrm{Fe}-30 \mathrm{Cr}$, and pure $\mathrm{Fe}$ is used as a substrate of $\mathrm{Ni}_{2} \mathrm{Al}_{3}$ and $\mathrm{NiAl}$ phases for aluminized $\mathrm{Ni}$ and of $\mathrm{Mo}_{3} \mathrm{Al}_{8}$ for Mo substrate [12]. Chromoaluminizing process can be carried out by one- or twostage method using pack cementation [6, 14-16, 18-20]. The chemical composition of powder mixture is crucial because it highly influences the coating properties. This composition, as well as its influence on microstructure, concentration profiles of elements and oxidation resistance, has been analyzed in the studies [14, 15]. Fluidized bed chemical vapor deposition can also be applied in order to obtain chromoaluminized coating. This method combines the characteristics of a fluidized bed reactor, uniform temperature, gas distribution and complete mixing of the reacting elements [21].

Till date, lack of reports on aluminizing processes modified by chromium on Ni-based alloys exists. To gain new information about this phenomenon, we have used the following procedure. A powder mixture with a composition of $\mathrm{Al}$ and $\mathrm{Fe}-\mathrm{Cr}$ (as a source of $\mathrm{Cr}$ ), $\mathrm{NH}_{4} \mathrm{Cl}$ (as an activator) and kaolin as an inert filler was used. The one-step pack cementation method was investigated. The microstructures, chemical and phase compositions, hardness and heat resistance of aluminized coatings modified by chromium on Ni-based alloys were presented (Inconel 600, Inconel 625 and Nimonic 90). For the first time, we have shown the usefulness of confocal microscopy for nickel alloys' microstructure studies. Finally, we have shown great improvement in the nickel-based alloys properties. This investigation has shown that the aluminizing layers can be very interesting in high-temperature applications. Other investigations [2, 22, 23] show that, during working condition, on the nickel alloys surface, a lot of oxides are produced. But these oxides does not protect the surface from oxidation at high temperatures. Aluminizing process allows protection of the surface of $\mathrm{Ni}$ alloys by producing, during oxidation, the continuous and compact layer which consist of the alumina and chromium oxides $\left(\mathrm{Al}_{2} \mathrm{O}_{3}\right.$ and $\mathrm{Cr}_{2} \mathrm{O}_{3}$, respectively) on Nimonic 90 alloy.

\section{Experimental Details}

\subsection{Materials}

Inconel 600, 625 and Nimonic 90 alloys were investigated. The roller specimens were used for the study. These alloys are widely used in wide range of applications, especially those which are working at high temperature [24-26]. Chemical composition of these materials is given in Table 1.

\subsection{Chromoaluminizing Process}

The powder mixture consisted of $60 \% \mathrm{w} / \mathrm{w}$ of metallic part (80Al-20Fe-Cr), $39.5 \% \mathrm{w} / \mathrm{w}$ of kaolin and $0.5 \% \mathrm{w} / \mathrm{w}$ $\mathrm{NH}_{4} \mathrm{Cl}$ as activator. The powder mixture was dried in $150{ }^{\circ} \mathrm{C}$ for $24 \mathrm{~h}$. The specimens were placed in a heatresistant steel tube. This tube was positioned on the vertical furnace which was heated to $950{ }^{\circ} \mathrm{C}$. The process lasted for $4 \mathrm{~h}$.

\subsection{Microstructure Analysis and Surface Condition}

The microstructure of the polished and etched cross section of the specimens was observed. For this purpose, scanning electron microscope Tescan Vega 5135 and confocal scanning microscope Zeiss LSM 710 were used. Confocal images were observed using a wavelength of $458 \mathrm{~nm}$ emitted from argon laser. Microscope worked in the

Table 1 Chemical composition of nickel-based alloys

\begin{tabular}{|c|c|c|c|c|c|c|c|c|c|c|c|c|c|c|}
\hline & \multicolumn{14}{|c|}{ Content $[w t \%]$} \\
\hline & $\begin{array}{l}\mathrm{Ni} \\
\mathrm{min}\end{array}$ & $\begin{array}{l}\mathrm{Cr} \\
-\end{array}$ & $\begin{array}{l}\mathrm{Fe} \\
-\end{array}$ & $\begin{array}{l}\mathrm{C} \\
\max \end{array}$ & $\begin{array}{l}\text { Mn } \\
\max \end{array}$ & $\begin{array}{l}\mathrm{S} \\
\max \end{array}$ & $\begin{array}{l}\mathrm{Si} \\
\max \end{array}$ & $\begin{array}{l}\mathrm{Cu} \\
\max \end{array}$ & $\begin{array}{l}\text { Mo } \\
-\end{array}$ & $\begin{array}{l}\mathrm{Nb} \\
-\end{array}$ & $\begin{array}{l}\mathrm{Al} \\
\max \end{array}$ & $\begin{array}{l}\mathrm{Ti} \\
\max \end{array}$ & $\begin{array}{l}\mathrm{P} \\
\max \end{array}$ & $\begin{array}{l}\text { Co } \\
\max \end{array}$ \\
\hline Inconel 600 & 72.0 & 15.5 & 8.0 & 0.15 & 1.0 & 0.015 & 0.5 & 0.5 & - & - & - & - & - & - \\
\hline Inconel 625 & 58.0 & 21.5 & 5.0 & 0.10 & 0.5 & 0.015 & 0.5 & - & 9.0 & 3.5 & 0.4 & 0.4 & 0.015 & 0.5 \\
\hline Nimonic 90 & balance & 19.5 & 1.5 & 0.13 & 1.0 & 0.015 & 1.0 & 0.2 & - & - & 1.5 & 2.5 & - & 18.0 \\
\hline
\end{tabular}


Fig. 1 Microstructure of aluminized layers, modified by chromium, produced on: a, b Inconel 600; c, d Inconel 625; e, f Nimonic 90; a, c, e confocal microscope, $\mathbf{b}, \mathbf{d}, \mathbf{f}$ scanning electron microscope
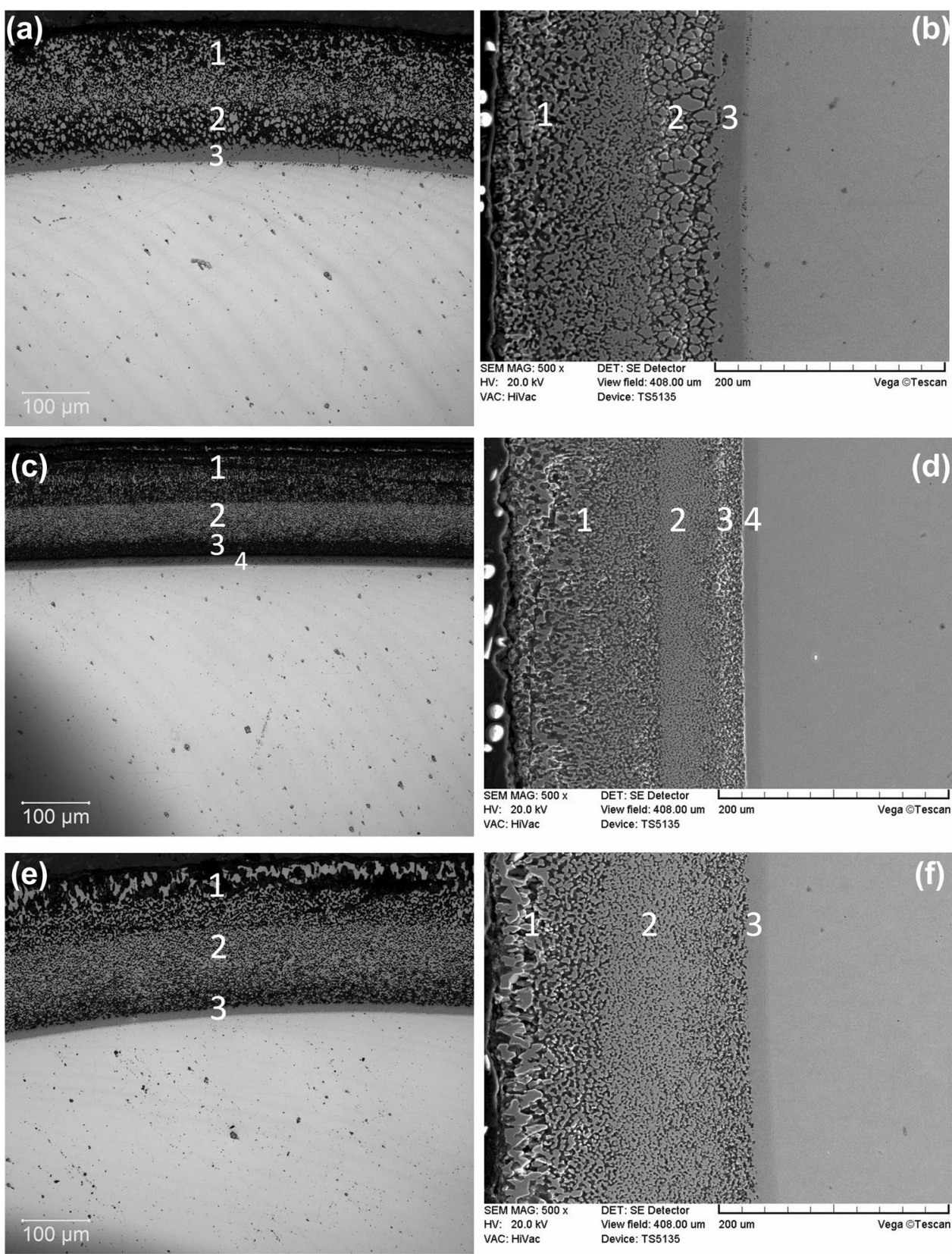

materials mode (reflection light) during measurements. After the aluminizing process, the specimens were polished using abrasive paper with different granularity, and afterward $\mathrm{Al}_{2} \mathrm{O}_{3}$ was exploited. To reveal the microstructure of diffusion coatings and materials, the etching solution consisting of copper (II) sulfate $\left(\mathrm{CuSO}_{4}\right)$, hydrochloric acid $(\mathrm{HCl})$ and water $\left(\mathrm{H}_{2} \mathrm{O}\right)$ was applied.

\subsection{Microhardness Profiles}

On the polished cross section of specimens, microhardness profiles were measured. The Vickers method and Buehler
Micromet II apparatus were used for the measurement, which was carried out at the load of $P=50 \mathrm{G}(0.491 \mathrm{~N})$.

\subsection{Oxidation Test}

The specimens were placed in the furnace in the ceramic boats. The parameters of the study were: temperature $1000{ }^{\circ} \mathrm{C}$, cycle time $2 \mathrm{~h}$ and 10 cycles. After that, the specimens were cooled down to the room temperature and weighed. The heat resistance was described by the weight change with respect to the total area of specimens. 


\subsection{X-ray Microanalysis and Phase Analysis}

Diffractometer with $\mathrm{Cu} \mathrm{K} \alpha$ radiation PANalytical Empyrean was used for the phase analysis by X-ray diffraction of the coatings. The chemical composition of prepared layers was investigated by X-ray microanalyzer PGT Avalon equipped with EDS $55^{\circ}$ takeoff angle, and the accelerating voltage was $12 \mathrm{kV}$.

\section{Results and Discussion}

\subsection{Microstructure}

The microstructure of prepared aluminizing layers, modified by chromium, is shown in Fig. 1. The layers are multizones and multiphases. In Fig. 1a, b, the microstructure of Inconel 600 is shown. Three zones are observed; the first one contain bright small intermetallic phase. In the next zone, intermetallic phases are bigger than in the first zone. Between these phases, the dark area is observed, which is probably the constant solution. The last zone in these layers is the continuous area with good adherence to the base material aluminizing layers prepared on Inconel 625 which are shown in Fig. 1c, d. In the figure, four zones strictly adhering to each other are easily noticeable. In the first two zones, a large amount of bright intermetallic phases is observed. These phases are also observed in the layer on the Inconel 600. The next zone consist of dark, probably intermetallic phases. The last zone is characterized by good adhesion to the base material.

Microstructure of Nimonic 90 alloy with aluminizing layers is shown in Fig. 1e, f. This layer is more uniform than the other layers. This layer consist of three zones. In the first one, the large intermetallic phases are observed. In the next zone, the intermetallic phases are smaller than in the first zone. The last zone is probably the constant solution, which has good bond with the base material.

Very similar results, i.e., microstructure and the same intermetallic phases, are obtained and have been reported recently $[2,17,27]$. In microstructure of each sample, the intermetallic phases are probably: $\gamma-\mathrm{NiAl}, \gamma^{\prime}-\mathrm{Ni}_{3} \mathrm{Al}$ and $\alpha \mathrm{Cr}$ between them.

\subsection{Microhardness Studies}

The microhardness of aluminized layers produced on nickel alloys is shown in Fig. 2. The layers produced on Nimonic 90 are characterized by 908.9 HV0.05 microhardness, and these layers have the highest hardness in comparison with the others. Inconel 600 and Inconel 625 displays 739.2 HV0.05 and 825.2 HV0.05 of microhardness, respectively. The microhardness of transition zones,

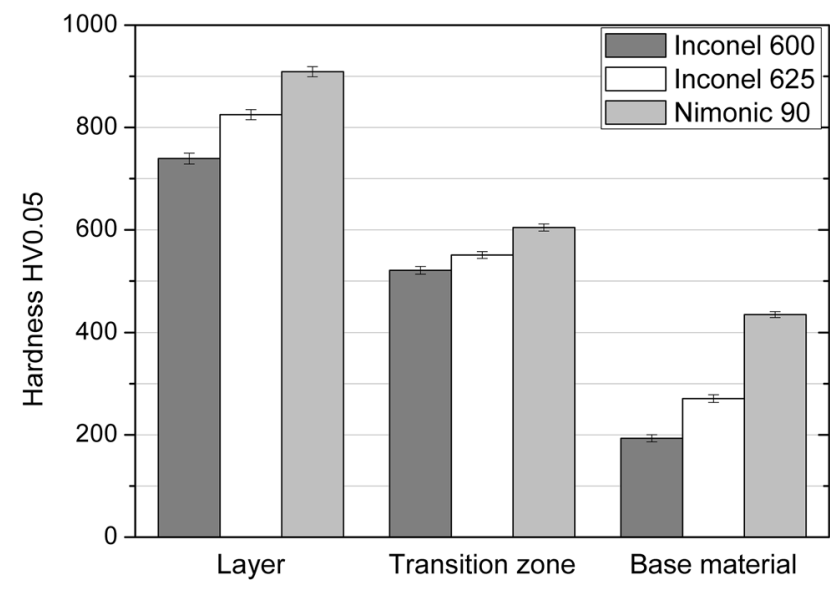

Fig. 2 Microhardness measurements of aluminized layers, modified by chromium, produced on the nickel alloys

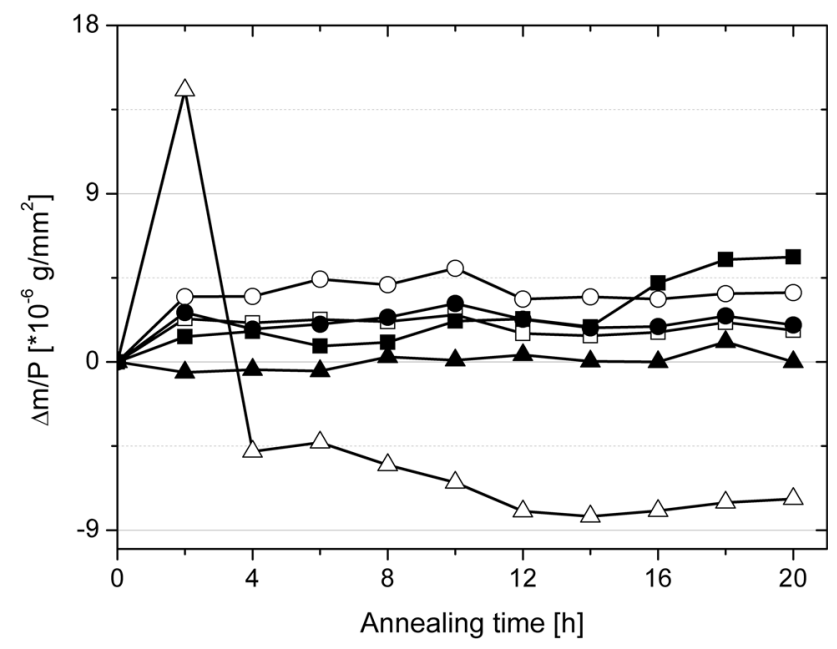

Fig. 3 Mass changes with respect to the surface area of the samples as a function of annealing time performed at $1000{ }^{\circ} \mathrm{C}$ for Inconel 600 , Inconel 625 and Nimonic 90 (square, circle and triangle, respectively), without layer opened and with layer closed symbols

which displays good adherence to the basic material (probably it was a constant solution $\mathrm{Cr}$ and $\mathrm{Al}$ in $\mathrm{Ni}$ ), has a larger value for Nimonic 90 (604.5 HV0.05), second is Inconel $625-550.8 \mathrm{HV0.05}$, and the last one is Inconel 600 -520.9 HV0.05. Each layer has a beneficial gradient of hardness, which is revealed in the mild decrease in this parameter with increased distance from the surface. In comparison, the microhardness of aluminizing layers which are produced on Armco iron, St 3 and gray cast iron are $745 \mathrm{HV}, 811 \mathrm{HV}$ and $1450 \mathrm{HV}$, respectively [28]. Also, on the nickel alloys, boriding with titanizing treatment can be applied. In this case, the microhardness of these layers are approximately $2514 \div 3354$ HV0.005 because the layers are made from tough borides such as $\mathrm{TiB}_{2}$ [29]. However, after boriding itself, nickel alloys are 

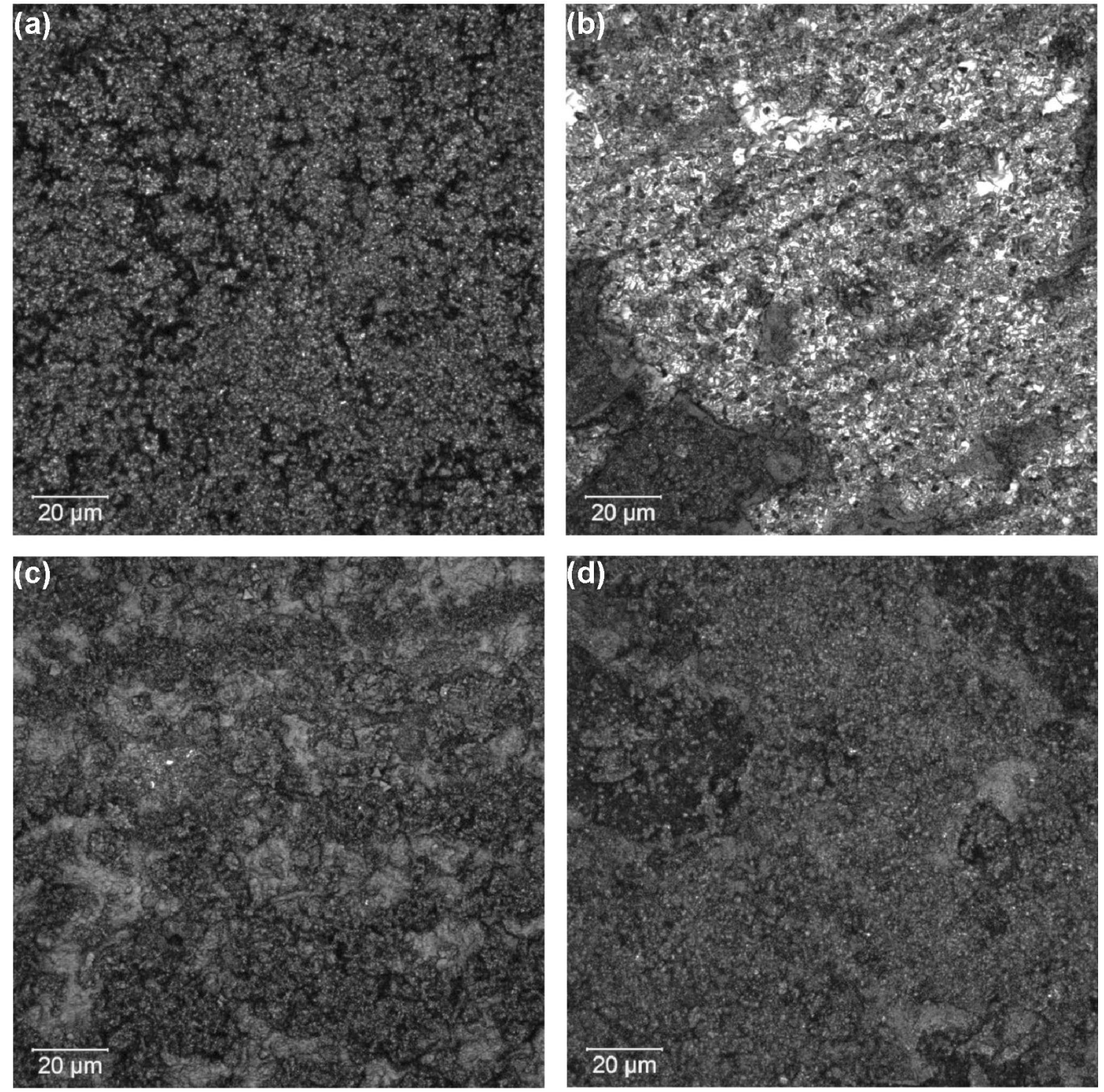

Fig. 4 Surface of Inconel 600 sample after annealing at $1000{ }^{\circ} \mathrm{C}$ for: $2 \mathrm{~h}(\mathbf{a}, \mathbf{b}) ; 20 \mathrm{~h}(\mathbf{c}, \mathbf{d}) ; \mathbf{a}, \mathbf{c}$ without layer, b, d with layer. Images obtained by means of confocal microscopy

characterized by microhardness equal to $1200 \div$ 1600 HV0.05 [30].

\subsection{Hot Oxidation Examination}

In Fig. 3, the results of oxidation in elevated temperature tests are shown. Curves for Inconel 600 with the layer are characterized by smaller mass losses than the base material after $10 \mathrm{~h}$ of annealing. Some spalls are observed on the sample with the layer after this time. These spalls indicates that the loss of mass is bigger for the sample with layer.

In case of the Inconel 625, the sample with the layer displays better heat resistance, which is reflected in lower mass loss in comparison with base material, after the total time of annealing.
Nimonic 90 without layers is characterized by variable course of mass changes. After $2 \mathrm{~h}$, the sample demonstrates a determined (considerable) increase in mass and proves to be the biggest of all samples. After $4 \mathrm{~h}$, a part of the layer separates and the mass of the sample dramatically decreases. Materials are characterized by high oxidation resistance when compact oxide layers are produced on their surface, without defects in the crystal structure. Because of that on the Nimonic 90 surface, the discontinuous oxide layers with a lot of defects are produced in the initial stage of hot corrosion. Defective structure causes a rapid weight gain because of the easy diffusion of oxygen on the sample's surface. After $2 \mathrm{~h}$ of oxidation, the discontinuous oxide layers are separated. Next, the surface is permanently oxidized. These oxide layers are probably obtained from 

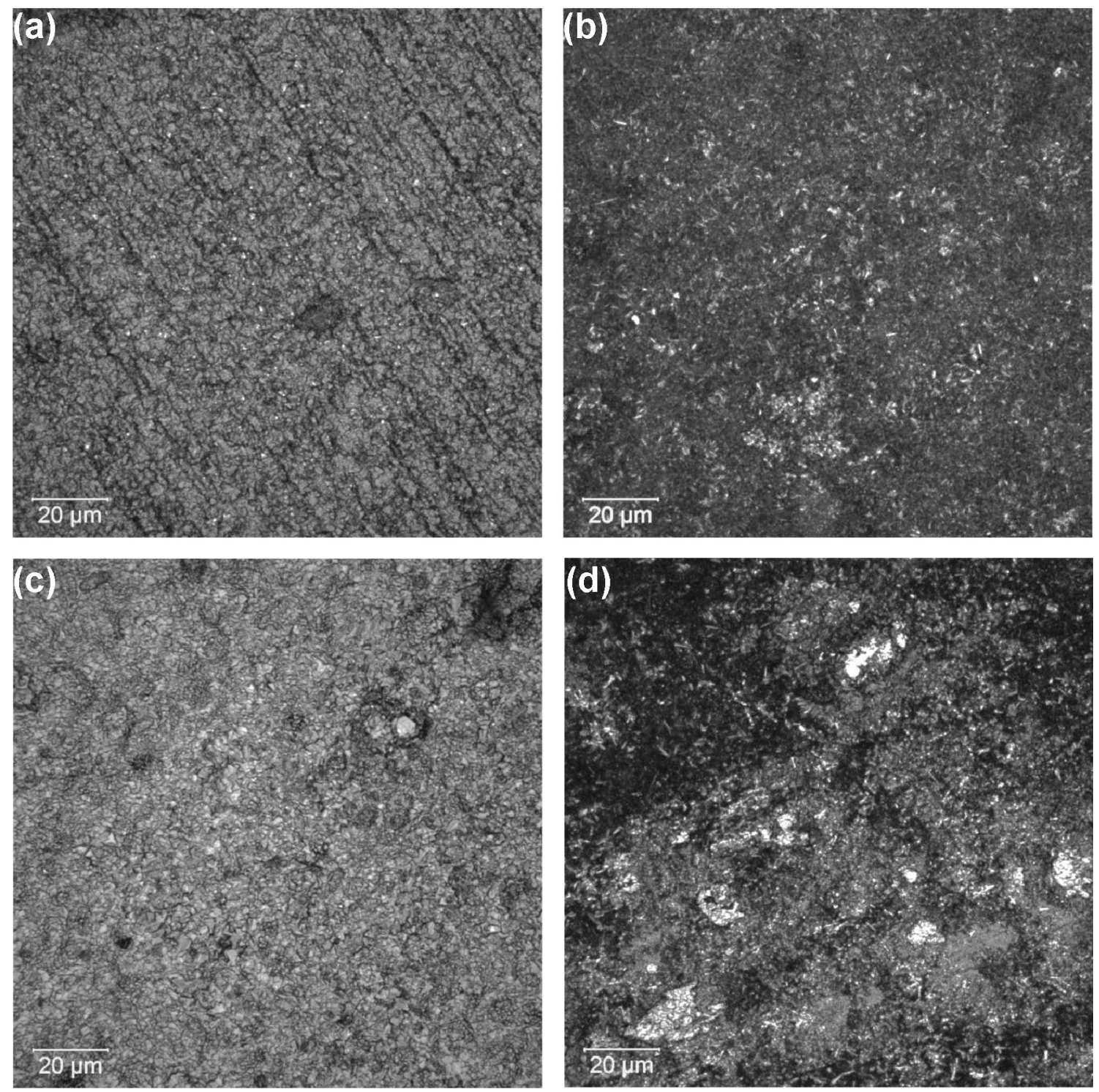

Fig. 5 Surface of Inconel 625 sample after annealing at $1000{ }^{\circ} \mathrm{C}$ for: $2 \mathrm{~h}(\mathbf{a}, \mathbf{b}) ; 20 \mathrm{~h}(\mathbf{c}, \mathbf{d}) ; \mathbf{a}, \mathbf{c}$ without layer, b, d with layer. Images obtained by means of confocal microscopy

nickel oxide $(\mathrm{NiO})$, which is characterized by very poor heat resistance and it does not protect the materials' surface. The sample with the layer shows only slight mass changes, thus displaying the best heat resistance quality among all the tested specimens.

In Figs. 4, 5 and 6, the surface condition of materials after 2 and $20 \mathrm{~h}$ of annealing at $1000{ }^{\circ} \mathrm{C}$ is shown. These figures indicate how the surface get altered after a longer time of annealing. Some of the changes may include: formation of the oxides and loss of mass, which occurs as a dark area in the figure. The smallest alterations are observed in Fig. 6 which shows the surface of Nimonic 90 with layers. Therefore, the Nimonic 90 with layer has the best heat resistance. The differences in heat resistance of each layers depended on the structure and properties of the layer as well as on types of oxides which are produced on the sample's surface. The aluminum $\left(\mathrm{Al}_{2} \mathrm{O}_{3}\right)$ and chromium $\left(\mathrm{Cr}_{2} \mathrm{O}_{3}\right)$ oxides are characterized by the best heat resistance; therefore, on the surface of Nimonic 90 with the layer these oxides are most likely to be produced [31]. The presence of these oxides on the Nimonic 90 surface can be proved by the phase analysis discussed in Sect. 3.4.

\subsection{Phase Analysis}

In Fig. 7, the XRD patterns of the Nimonic 90 with or without layers are shown. The phase analysis shows that on the surface, after annealing at $1000{ }^{\circ} \mathrm{C}$ for $20 \mathrm{~h}$, some oxides are produced: $\mathrm{Al}_{2} \mathrm{O}_{3}, \mathrm{NiO}$ and $\mathrm{Cr}_{2} \mathrm{O}_{3}$. On the samples is without layer (Fig. 7a), mainly the $\mathrm{NiO}$ oxides are 

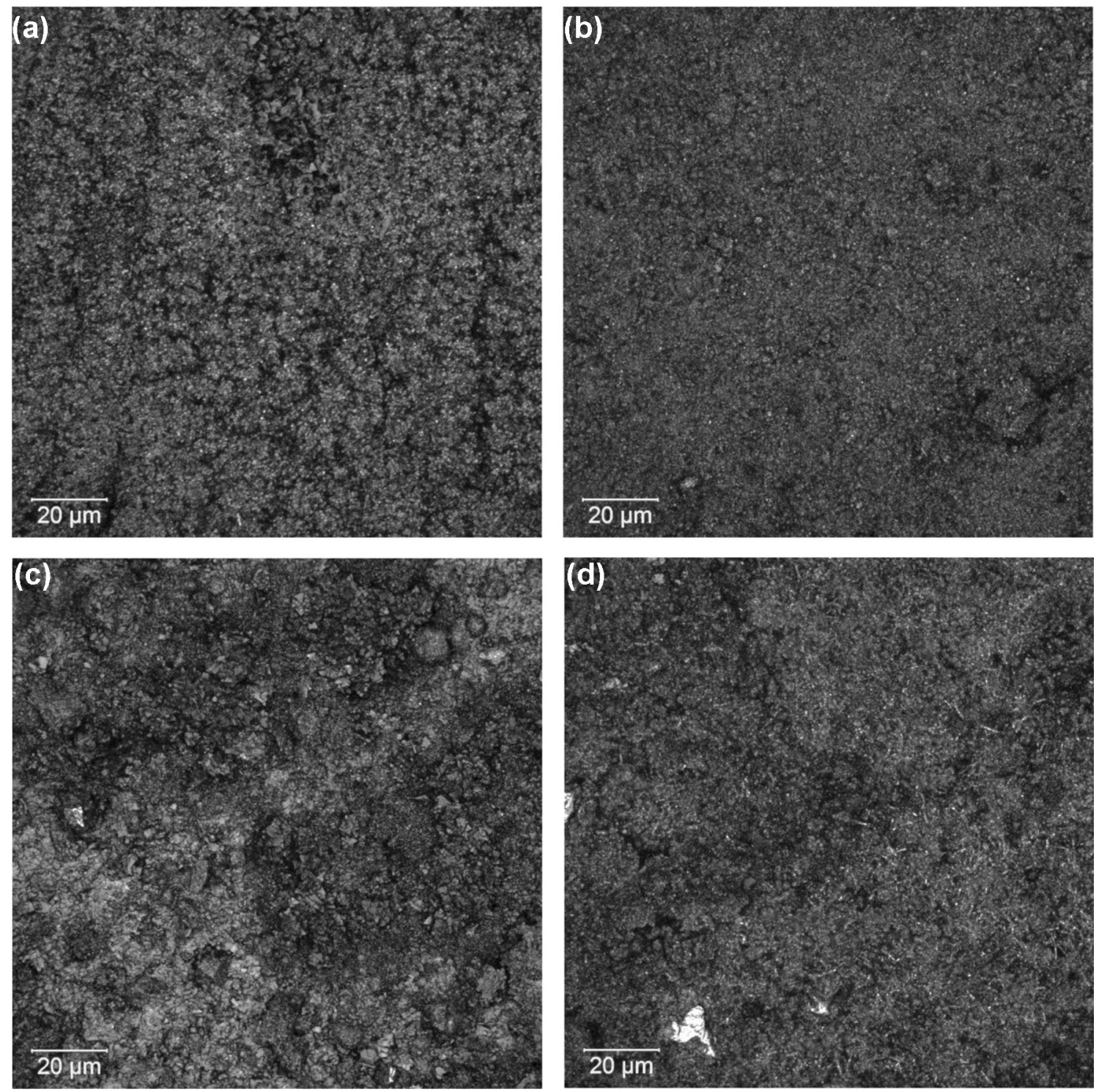

Fig. 6 Surface of Nimonic 90 sample after annealing at $1000{ }^{\circ} \mathrm{C}$ for: $2 \mathrm{~h}(\mathbf{a}, \mathbf{b}) ; 20 \mathrm{~h}(\mathbf{c}, \mathbf{d}) ; \mathbf{a}, \mathbf{c}$ without layer, b, d with layer. Images obtained by means of confocal microscopy

produced. This discontinuous layer does not protect the materials against oxidation, which penetrates the base materials, especially through grain boundaries [5]. However, on the sample with the layer (Fig. 7b), the following oxides occur: $\mathrm{Al}_{2} \mathrm{O}_{3}$ and $\mathrm{Cr}_{2} \mathrm{O}_{3}$. These oxides form the protective layer, which protect the base material against oxidation.

\subsection{X-ray Microanalysis}

\subsubsection{Linear X-ray Microanalysis}

In Fig. 8a, the linear X-ray microanalysis, of aluminized layer, modified by chromium, produced on Inconel 600 is shown. At first, it is easy to notice that the amount of chrome is very low, but the values of aluminum and nickel are higher. The intermetallic phase contains very low contents of chrome. It can be observed that the positive and negative peaks of nickel overlap with negative and positive peaks of aluminum, respectively, which means these elements displace each other in the individual areas of layers. From the distance of $150 \mu \mathrm{m}$ from the surface, the content of chrome increases, which means intermetallic phases have higher amounts of chrome and less of nickel and aluminum. Chrome and nickel reaches the largest content in the transition zone, but the aluminum still decreases. This zone is probably the solid solution of chrome and aluminum in nickel. After the transition zone, the content of each element reaches the value characteristic for the base material. 

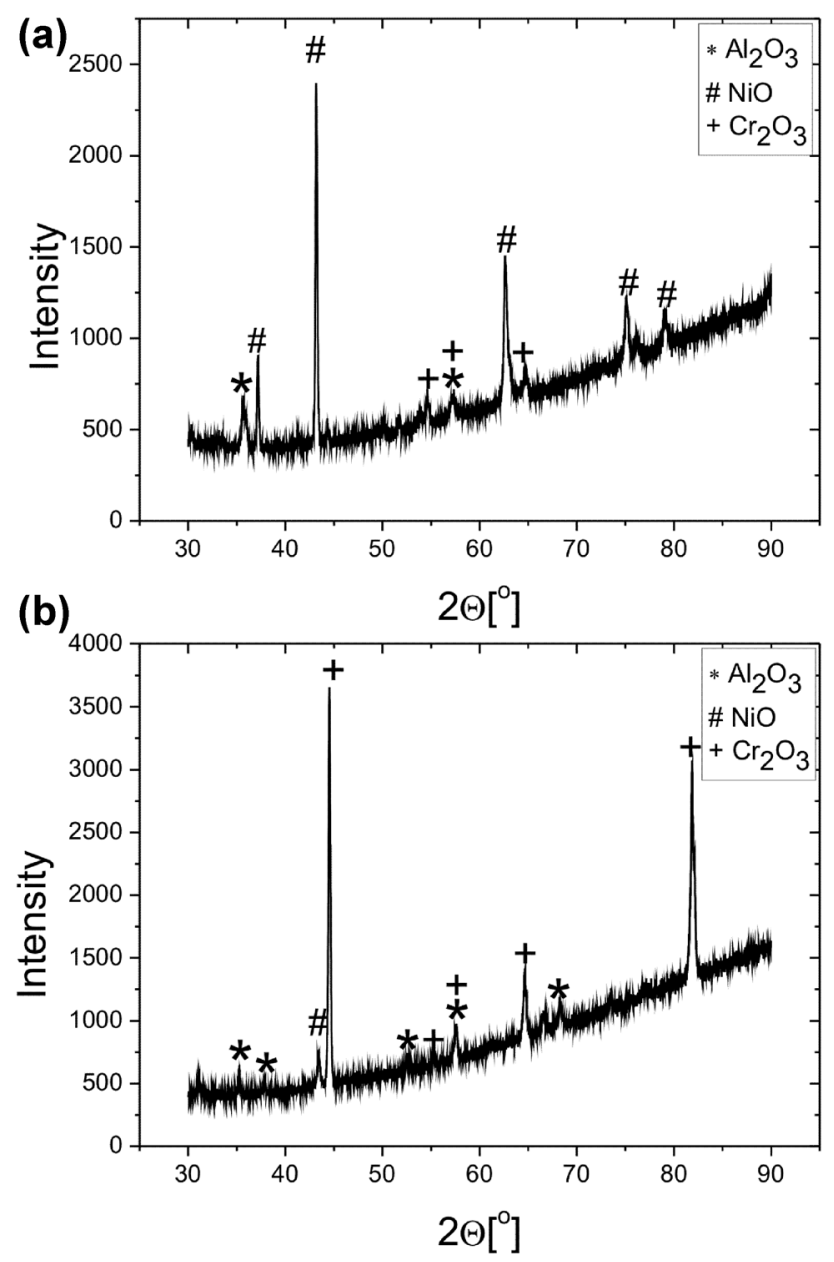

Fig. 7 XRD patterns of Nimonic 90 after annealing at $1000{ }^{\circ} \mathrm{C}$ for $20 \mathrm{~h}$ : a without layer, $\mathbf{b}$ with layer

In Fig. 8b, the linear X-ray microanalysis, of aluminized layer, modified by chromium, produced on Inconel 625 is shown. Lines of chrome, aluminum and nickel have very similar variations to the lines in Fig. 8a. In the case of this material, the variation of molybdenum can be measured. The negative and positive peaks of molybdenum are observed, and these peaks overlap with peaks from aluminum and nickel. In the transition zone, the content of aluminum decreases to the amount which is characteristic for the base material, while the amount of other elements increases.

The microanalysis of aluminized layer, modified by chromium, produced on Nimonic 90 is shown in Fig. 8c. The analysis includes the following elements: nickel, chrome, aluminum, titanium and cobalt. In this layer, the content of aluminum and nickel have the highest value and variation is was very similar to the previous layers. At a distance of $100 \mu \mathrm{m}$ from the surface, the positive peak of chrome is observed. This peak overlaps with negative peaks of nickel and aluminum, which means chrome
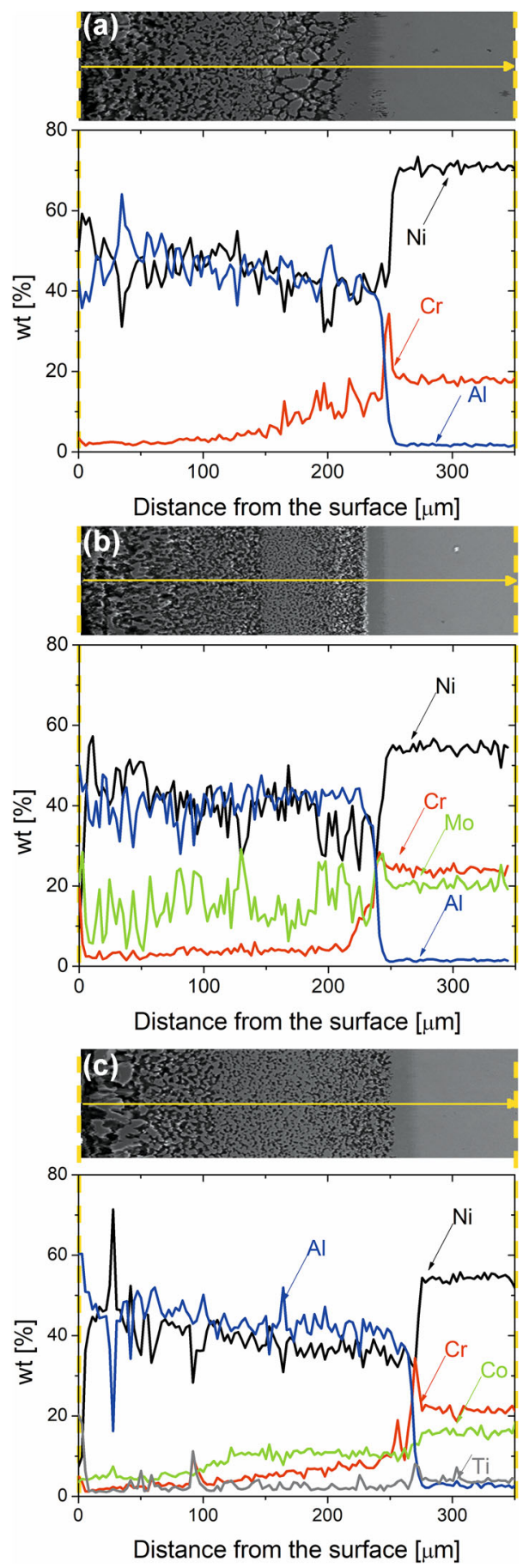

Fig. 8 Results of linear X-ray microanalysis of Inconel 600 (a), Inconel 625 (b) and Nimonic 90 (c) aluminized and modified by chromium

displaces these two elements and the phase with a lot of chrome is produced. The content of chrome in the layer is very low, but the amount of cobalt rises from the surface to the base material. The trace amount of titanium is observed. 

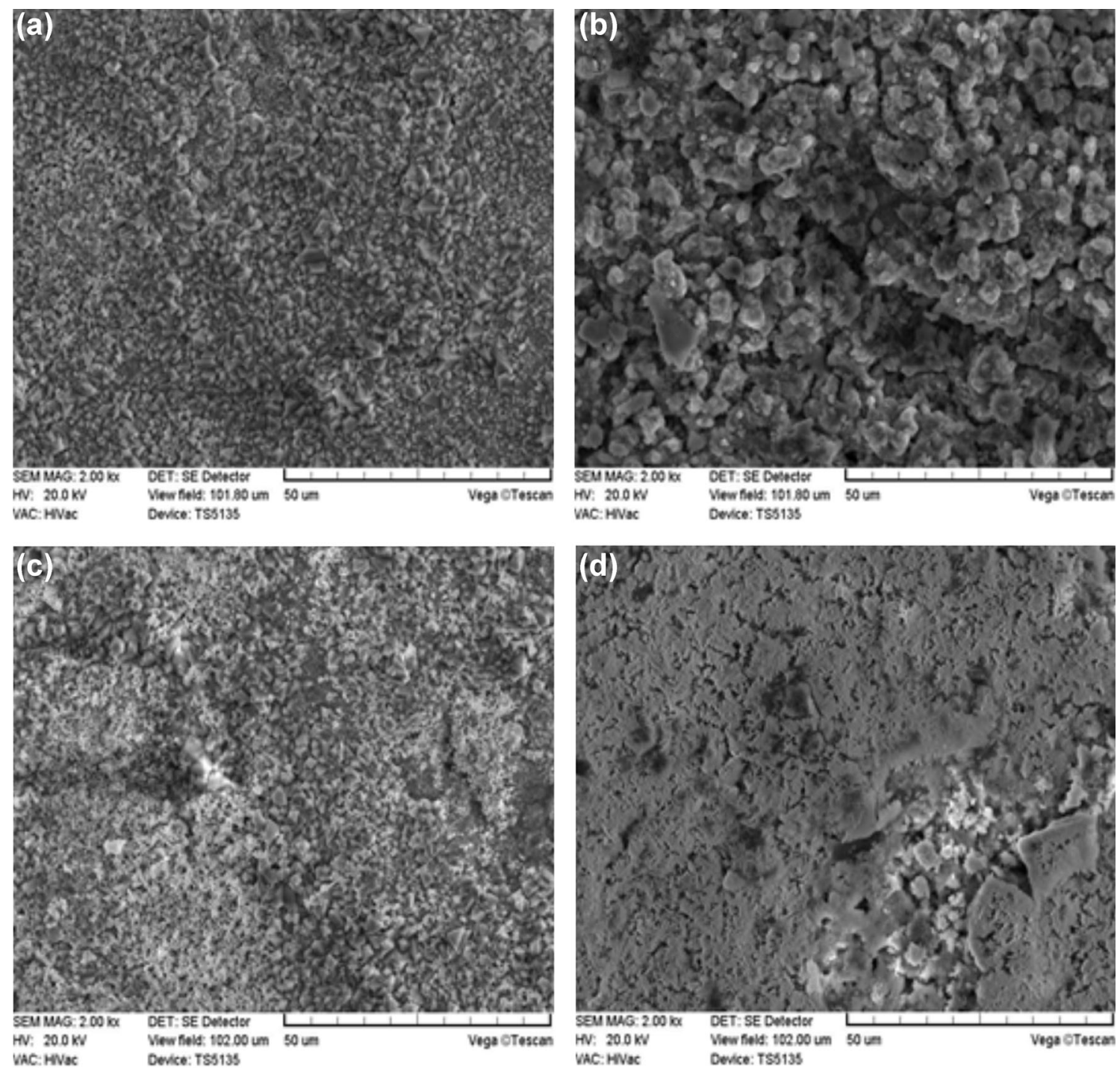

Fig. 9 Surface condition of Inconel 600 alloy after annealing for: $10 \mathrm{~h}-\mathbf{a}$ without layer, b with layer; $20 \mathrm{~h}-\mathbf{c}$ without layer, $\mathbf{d}$ with layer (scanning electron microscope)

Table 2 Chemical composition of sample's surface after annealing for 10 and $20 \mathrm{~h}$

\begin{tabular}{|c|c|c|c|c|c|c|c|c|}
\hline \multirow[b]{3}{*}{ Element } & \multicolumn{4}{|l|}{$10 \mathrm{~h}$} & \multicolumn{4}{|l|}{$20 \mathrm{~h}$} \\
\hline & \multicolumn{2}{|c|}{ Inconel 600} & \multicolumn{2}{|c|}{ Inconel 600 with layer } & \multicolumn{2}{|c|}{ Inconel 600} & \multicolumn{2}{|c|}{ Inconel 600 with layer } \\
\hline & wt $\%$ & at $\%$ & wt $\%$ & at $\%$ & $\mathrm{wt} \%$ & at $\%$ & $\mathrm{wt} \%$ & at $\%$ \\
\hline $\mathrm{O}$ & 11.68 & 32.25 & 18.20 & 30.81 & 12.30 & 33.45 & 27.62 & 40.02 \\
\hline $\mathrm{Cr}$ & 11.09 & 9.42 & 4.63 & 2.41 & 13.59 & 11.37 & 1.47 & 0.66 \\
\hline $\mathrm{Fe}$ & 5.85 & 4.63 & 1.91 & 0.93 & 6.06 & 4.72 & 0.51 & 0.21 \\
\hline $\mathrm{Ni}$ & 71.37 & 53.71 & 17.92 & 8.27 & 68.05 & 50.45 & 3.02 & 1.19 \\
\hline $\mathrm{Al}$ & - & - & 57.34 & 57.58 & - & - & 67.38 & 57.92 \\
\hline
\end{tabular}



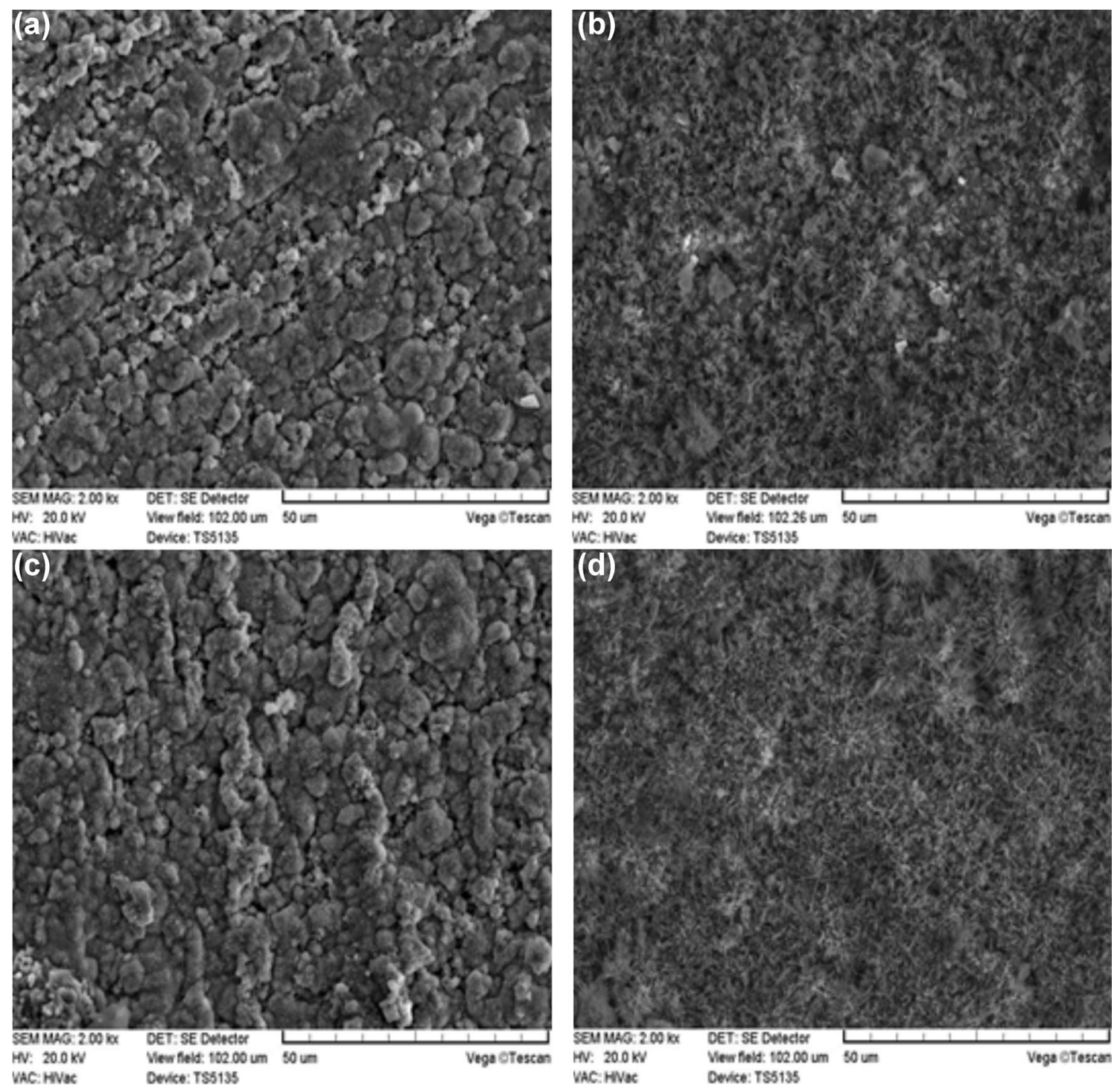

Fig. 10 Surface condition of Inconel 625 alloy after annealing for: $10 \mathrm{~h}-\mathbf{a}$ without layer, $\mathbf{b}$ with layer; $20 \mathrm{~h}-\mathbf{c}$ without layer, $\mathbf{d}$ with layer (scanning electron microscope)

\subsubsection{Chemical Composition Analysis After Annealing at $1000{ }^{\circ} \mathrm{C}$}

Surface condition of Inconel 600 samples, with and without layer, after annealing at $1000{ }^{\circ} \mathrm{C}$ for $10 \mathrm{~h}$ is shown in Fig. 9. The chemical composition of these areas was measured and is given in Table 2. These results indicate that the chrome and nickel oxides were produced on the sample without layer, whereas on the surface of the sample with the layer the amount of chrome and nickel oxides was reduced instead of aluminum oxides. Sample without layer was more uniform and compact. After annealing for $20 \mathrm{~h}$, the samples showed a similar behavior like that after $10 \mathrm{~h}$ (Table 2).

In Fig. 10, the surface of Inconel 625 after annealing at $1000{ }^{\circ} \mathrm{C}$ for $10 \mathrm{~h}$ can be observed. The sample without the layer has large grains and extensive topography. Analysis of chemical composition proves that on the surface, a lot of chrome oxides are produced (Table 3 ). While on the surface of the sample with the layer, less amount of chrome oxides but a lot of aluminum oxides are produced. After $20 \mathrm{~h}$ of annealing, the changes in chemical composition are identical such as that after $10 \mathrm{~h}$. The difference can be observed in the microstructure of samples: without layer has large grains, but this with layer is very uniform and compact.

Surface condition of Nimonic 90 alloys which are annealed for $10 \mathrm{~h}$ and $20 \mathrm{~h}$ is shown in Fig. 11, and the chemical composition of sample's surface is given in Table 4. Sample with no layer, after $10 \mathrm{~h}$ of annealing, is built with large grains, and dark area is located below the bright one. Sample with layer is more uniform. Analysis of 
Table 3 Chemical composition of sample's surface after annealing for 10 and $20 \mathrm{~h}$

\begin{tabular}{|c|c|c|c|c|c|c|c|c|}
\hline \multirow[b]{3}{*}{ Element } & \multicolumn{4}{|l|}{$10 \mathrm{~h}$} & \multicolumn{4}{|l|}{$20 \mathrm{~h}$} \\
\hline & \multicolumn{2}{|c|}{ Inconel 625} & \multicolumn{2}{|c|}{ Inconel 625 with layer } & \multicolumn{2}{|c|}{ Inconel 625} & \multicolumn{2}{|c|}{ Inconel 625 with layer } \\
\hline & $\mathrm{wt} \%$ & at $\%$ & $\mathrm{wt} \%$ & at $\%$ & $\mathrm{wt} \%$ & at $\%$ & wt $\%$ & at $\%$ \\
\hline $\mathrm{O}$ & 14.90 & 36.32 & 25.02 & 37.69 & 15.57 & 37.51 & 24.62 & 37.07 \\
\hline $\mathrm{Cr}$ & 80.88 & 60.67 & 2.71 & 1.26 & 79.72 & 59.11 & 2.45 & 1.13 \\
\hline $\mathrm{Fe}$ & 0.54 & 0.38 & 0.17 & 0.07 & 1.15 & 0.79 & 0.36 & 0.15 \\
\hline $\mathrm{Ni}$ & 1.43 & 0.95 & 6.87 & 2.82 & 1.44 & 0.95 & 6.18 & 2.54 \\
\hline $\mathrm{Al}$ & 0.35 & 0.50 & 64.99 & 58.08 & 0.33 & 0.47 & 66.10 & 59.03 \\
\hline $\mathrm{Ti}$ & 0.99 & 0.80 & 0.07 & 0.04 & 1.10 & 0.89 & 0.00 & 0.00 \\
\hline Мо & 0.92 & 0.37 & 0.17 & 0.04 & 0.70 & 0.28 & 0.30 & 0.07 \\
\hline
\end{tabular}
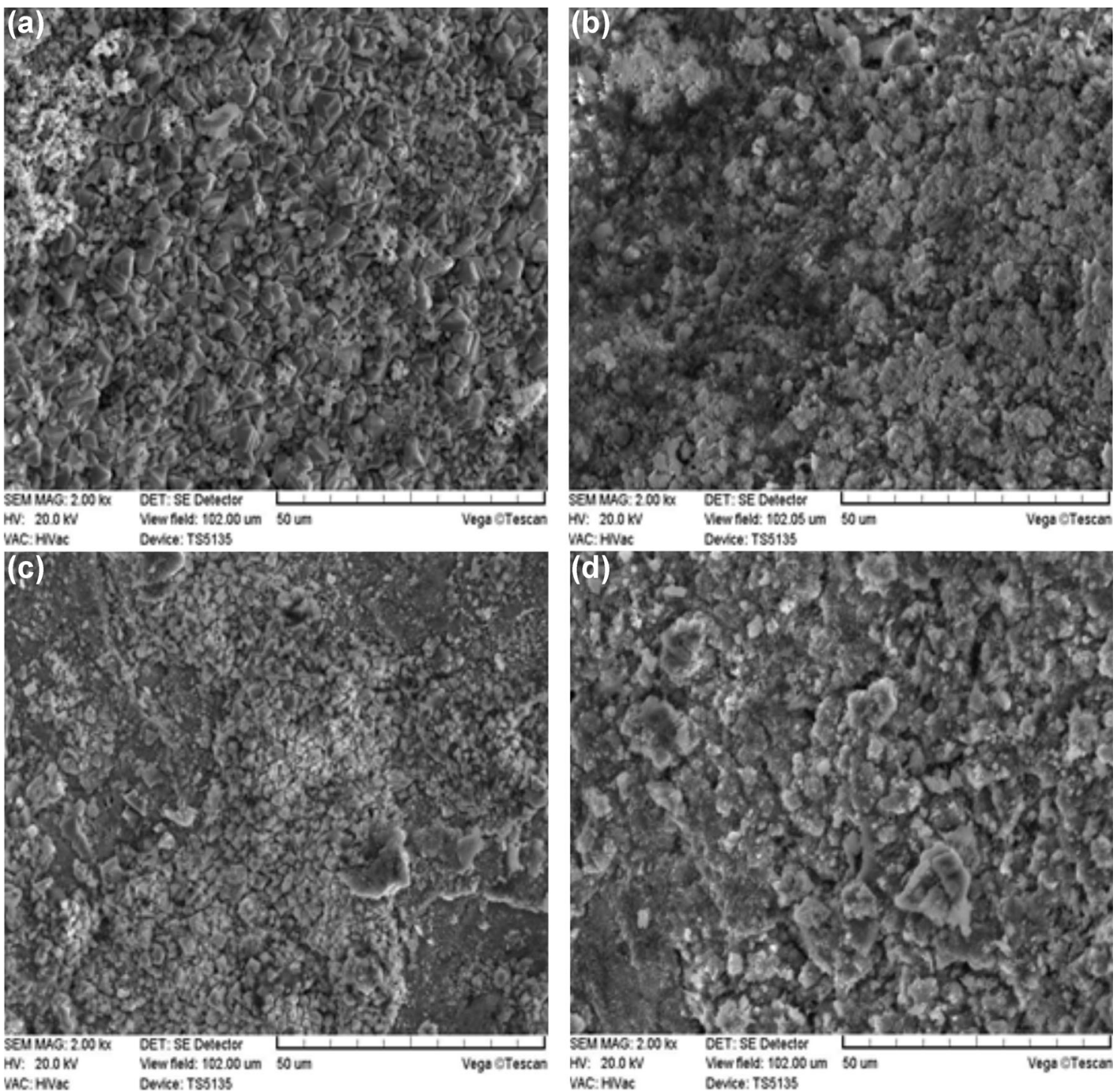

Fig. 11 Surface condition of Nimonic 90 alloy after annealing for: $10 \mathrm{~h}-\mathbf{a}$ without layer, $\mathbf{b}$ with layer; $20 \mathrm{~h}-\mathbf{c}$ without layer, $\mathbf{d}$ with layer (scanning electron microscope) 
Table 4 Chemical composition of sample's surface after annealing for 10 and $20 \mathrm{~h}$

\begin{tabular}{|c|c|c|c|c|c|c|c|c|}
\hline \multirow[b]{3}{*}{ Element } & \multicolumn{4}{|l|}{$10 \mathrm{~h}$} & \multicolumn{4}{|l|}{$20 \mathrm{~h}$} \\
\hline & \multicolumn{2}{|c|}{ Nimonic 90} & \multicolumn{2}{|c|}{ Nimonic 90 with layer } & \multicolumn{2}{|c|}{ Nimonic 90} & \multicolumn{2}{|c|}{ Nimonic 90 with layer } \\
\hline & $\mathrm{wt} \%$ & at $\%$ & $\mathrm{wt} \%$ & at $\%$ & $\mathrm{wt} \%$ & at $\%$ & $\mathrm{wt} \%$ & at $\%$ \\
\hline $\mathrm{O}$ & 8.16 & 24.23 & 30.91 & 44.26 & 8.78 & 25.25 & 20.49 & 32.54 \\
\hline $\mathrm{Cr}$ & 4.52 & 4.13 & 2.46 & 1.08 & 13.83 & 12.25 & 2.52 & 1.23 \\
\hline $\mathrm{Fe}$ & 0.10 & 0.09 & 0.17 & 0.07 & 0.31 & 0.26 & 0.01 & 0.00 \\
\hline $\mathrm{Ni}$ & 71.68 & 57.99 & 2.28 & 0.89 & 56.57 & 44.38 & 8.42 & 3.65 \\
\hline $\mathrm{Al}$ & 0.93 & 1.63 & 62.08 & 52.74 & 1.08 & 1.84 & 64.16 & 60.46 \\
\hline Co & 13.73 & 11.06 & 0.53 & 0.21 & 14.76 & 11.53 & 2.23 & 0.96 \\
\hline $\mathrm{Ti}$ & 0.88 & 0.87 & 1.57 & 0.75 & 4.67 & 4.49 & 2.17 & 1.15 \\
\hline
\end{tabular}

chemical composition shows that the sample with layer absorbs more oxygen than the sample of pure alloy, and the aluminum oxides are produced. On the pure alloy, the nickel and chromium oxides are produced. After annealing for $20 \mathrm{~h}$, sample of pure alloy has small grains, but in some place, loss of material is observed. Sample with layer does not have a lot of changes in comparison with sample after $10 \mathrm{~h}$ of annealing. The nickel and chrome oxides are produced on the sample of pure alloy, but on the sample with layer, aluminum oxides are produced in large amount.

\section{Conclusions}

In conclusion, our results indicate that aluminized coatings, modified by chromium, produced on nickel-based alloys after chemical heat treatment had a surface in good condition, with small roughness, and layer loss was not observed. Aluminized layers are characterized by multiphase and multizone microstructure. Each layer was composed of bright intermetallic phases and solid solution, probably chrome and aluminum in nickel, which had good adherence to the base material. Layer which was produced on Nimonic 90 had the largest thickness in comparison with the layers produced on other materials. The layer on Inconel 625 had the smallest thickness.

The layer produced on Nimonic 90 had a higher hardness (908.9 HV0.05). Inconel 600 with the layer was characterized by smallest hardness which was equal to 739.2 HV0.05. Nimonic 90 after aluminization had the best heat resistance because after $20 \mathrm{~h}$ of annealing the mass change was scant, approximately equal to 0 .

The linear X-ray microanalysis proved that the distribution of element concentration was approximately equal for each material. In each layer, the amount of aluminum and nickel was higher, but the amount of chrome was on the lower level. Chemical composition analysis after annealing at $1000{ }^{\circ} \mathrm{C}$ proved that on the surface of pure alloy sample, the chrome and nickel oxides were produced. On the surface of the samples with the layer, the aluminum oxides were observed. These studies showed that the best layer was produced on the Nimonic 90 alloy. This layer had very good properties such as great thickness, high hardness and high heat resistance.

Acknowledgements This work has been financially supported by Ministry of Science and Higher Education in Poland as a part of the Project No. 02/24/DSPB.

Open Access This article is distributed under the terms of the Creative Commons Attribution 4.0 International License ( http://creativecommons.org/licenses/by/4.0/), which permits unrestricted use, distribution, and reproduction in any medium, provided you give appropriate credit to the original author(s) and the source, provide a link to the Creative Commons license, and indicate if changes are made.

\section{References}

1. Zheng M, and Rapp R, Oxid Met 49 (1998) 19.

2. Naeem M T, Jazayeri S A, and Rezamahdi N, Failure analysis of gas turbine blades, in Proc. 2008 IAJC-IJME International Conference (2008).

3. Eliaz N, Shemesh G, and Latanision R M, Eng Fail Anal 9 (2002) 31.

4. Okazaki M, Sci Technol Adv Mater 2 (2001) 357.

5. Rodriguez G P, García I, and Damborenea J, Oxid Met 58 (2002) 235.

6. Liu Z, Zhao X, and Zhou C, Corros Sci 92 (2015) 148.

7. Priest M S, and Zhang Y, Mater Corros 66 (2015) 1111.

8. Zhou C, Xu H, Gong S, and Young Kim K, Mater Sci Eng A 341 (2003) 169.

9. Wang D, and Shi Z, Appl Surf Sci 227 (2004) 255.

10. Lee J W, and Kuo Y C, Surf Coat Technol 200 (2005) 1225.

11. Warnes B M, DuShane N S, and Cockerill J E, Surf Coat Technol 148 (2001) 163.

12. Houngninou C, Chevalier S, and Larpin J P, Appl Surf Sci 236 (2004) 256. 
13. Xiang Z D, Rose S R, and Datta P K, Mater Sci Eng A 356 (2003) 136.

14. Heo N H, Kim M T, Shin J H, and Kim C Y, Surf Coat Technol 123 (2000) 227.

15. Heo N H, Kim M T, Shin J H, and Kim C Y, Surf Coat Technol 124 (2000) 39.

16. Moosa A, Ahmed J K, and Hoobi A, Chin J Aeronaut 20 (2007) 134.

17. Simonov V N, Abraimov N V, Shkretov Y P, Lukina V V, and Terekhin A M, Met Sci Heat Treat 49 (2007) 362.

18. Chaliampalias D, Papazoglou M, Tsipas S, Pavlidou E, Skolianos S, Stergioudis G, and Vourlias G, Appl Surf Sci 256 (2010) 3618.

19. Wang Y Q, Zhang Y, and Wilson D A, Surf Coat Technol 204 (2010) 2737.

20. Lin N, Guo J, Xie F, Zou J, Tian W, Yao X, Zhang H, and Tang B, Appl Surf Sci 311 (2014) 330.

21. Christoglou C, Voudouris N, and Angelopoulos G N, Surf Coat Technol 155 (2002) 51.

22. Kazempour-Liacy H, Abouali S, and Akbari-Garakani M, Eng Fail Anal 18 (2011) 517.
23. Poursaeidi E, Aieneravaie M, and Mohammadi M R, Eng Fail Anal 15 (2008) 1111.

24. Sun W, Qin X, Guo J, Lou L, and Zhou L, Mater Des 69 (2015) 70.

25. Srinivasa N, and Prasad Y V R K, J Mater Process Technol 51 (1995) 171.

26. Hu H X, Zheng Y G, and Qin C P, Nucl Eng Des 240 (2010) 2721.

27. Kolomytsev P T, Abraimov N V, and Semenov A, Met Sci Heat Treat 24 (1982) 140.

28. Tarasko D, and Mikhailichenko T A, Met Sci Heat Treat 18 (1976) 487.

29. Günen A, Kanca E, Çakir H, Karakaş M S, Gök M S, Küçük Y, and Demir M, Surf Coat Technol 311 (2017) 374.

30. Deng D W, Wang C G, Liu Q Q, and Niu T T, Trans Nonferr Met Soc China 25 (2015) 437.

31. Rani A, Bala N, and Gupota C M, Oxid Met 88 (2017) 621. 